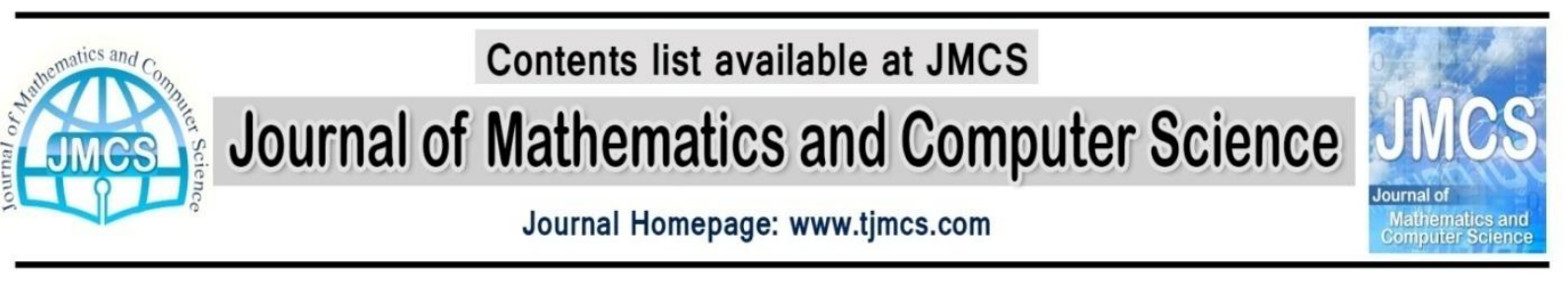

\title{
Common Fixed Point Theorem for Uniformly R-subweakly Commuting Mappings in Hausdorff Locally Convex Space
}

\author{
H. Shojaei, S. Dehghani \\ Department of Mathematics, Payame Noor Universi \\ Theran, Iran \\ hshojaei2000@yahoo.com
}

Article history:

Received April 2013

Accepted May 2013

Available online May 2013

\begin{abstract}
We show common fixed point theorem for generalized non-expansive and uniformly $R$-subweakly commuting mappings satisfying a more uniformly asymptotically regular condition in Hausdorff locally convex space.

Keywords : Uniformly $R$ - subweakly commuting mapping, non-expansive ,uniformly asymptotically regular .

\section{Introduction and Preliminaries}

With introduction of a class R-weakly commuting mappings, Pant obtained common fixed point results. We introduce a new class of commuting mappings namely $R$-subweakly commuting mappings and $R$-subcommuting mappings. Simultaneously, Hussain and Berinde [6] proved common fixed point results for generalized non-expansive $R$-subweakly commuting mappings on non-starshaped domain. More recently, Ismat Beg et al[2] extended Cho's result to asymptotically $I$ non-expansive mappings introducing a new class of non-commuting mappings as "uniformly $R$-subweakly commuting mappings". In this paper we present definition of uniformly $R$-subweakly commuting mappings on Hausdorff locally convex space that it is extension the definition of uniformly $R$-subweakly commuting on normed space.
\end{abstract}


The purpose of this paper is to generalize Beg's result for generalized asymptotically $I$ non-expansive and uniformly $R$-subweakly commuting mappings. Also we present a common fixed point lemma and apply it to find new common fixed point result. The existence of common fixed point is established for two mappings $T$ and $I$ that are uniformly $R$-subweakly commuting on a Hausdorff locally convex space.

Let $(X, \tau)$ be a Hausdorff locally convex topological vector space and $M$ be a $\tau$-bounded subset of $X$.

Definition 1.1: Let $(X, \tau)$ be a Hausdorff locally convex topological vector space. A family

$\left\{\mathrm{P}_{\alpha}: \alpha \in \mathrm{I}\right\}$ of semi-norms defined on $\mathrm{X}$ is said to be an associated family of semi-norms for $\tau$ if the family $\{r u: r>0\}$, where

$$
\begin{gathered}
\mathrm{u}=\bigcap_{\mathrm{i}=1}^{\mathrm{n}} \mathrm{u}_{\alpha_{\mathrm{i}} .} \\
\mathrm{u}_{\alpha_{\mathrm{i}}}=\left\{\mathrm{x}: \mathrm{P}_{\alpha_{\mathrm{i}}}(\mathrm{x})<1\right\} .
\end{gathered}
$$

forms a base of neighborhoods of zero for $\tau$. the associated family of semi norms for $\tau$ be denoted as $\mathrm{A}(\tau)$ Definition 1.2: A family $\left\{\mathrm{P}_{\alpha}: \alpha \in \mathrm{I}\right\}$ of semi-norms defined on $\mathrm{X}$ is called an augmented associated family for $\tau$ if $\left\{\mathrm{P}_{\alpha}: \alpha \in \mathrm{I}\right\}$ is an associated family with the property that the semi-norms,

$$
\max \left\{\mathrm{P}_{\alpha}, \mathrm{P}_{\beta}\right\} \in\left\{\mathrm{P}_{\alpha}: \alpha \in \mathrm{I}\right\} \text {. }
$$

for any $\alpha, \beta \in \mathrm{I}$. the augmented associated family of semi norms for $\tau$ be denoted by $\mathrm{A}^{*}(\tau)$.

Definition 1.3: A subset $M$ of $X$ is $\tau$-bounded iff each $P_{\alpha}$ is bounded on $M$.

Remark 1.4: If $M$ is a $\tau$-bounded subset of $\mathrm{X}$, then a number $\lambda_{\alpha}>0$ for each $\alpha \in \mathrm{I}$ is selected such that $M \subset \lambda_{\alpha} \mathrm{u}_{\alpha}$ where $\mathrm{u}_{\alpha}=\left\{\mathrm{x}: \mathrm{P}_{\alpha}(\mathrm{x}) \leq 1\right\}$. Clearly $\mathrm{B}=\bigcap_{\alpha} \lambda_{\alpha} \mathrm{u}_{\alpha}, \tau$ _closed and $\tau$ _bounded, absolutely convex and contains $M$.

Definition 1.5: let $T$ and $I$ be self-maps on $M$. The map $T$ is called

(1) $\mathrm{A}^{*}(\tau)$-nonexpansive if for all $x, y \in M$

$$
\mathrm{P}_{\alpha}(\mathrm{Tx}-\mathrm{Ty}) \leq \mathrm{P}_{\alpha}(\mathrm{x}-\mathrm{y})
$$

For each $\mathrm{P}_{\alpha} \in \mathrm{A}^{*}(\tau)$.

(2) $\mathrm{A}^{*}(\tau)-I$-nonexpansive if for all $x, y \in M$

$$
\mathrm{P}_{\alpha}(\mathrm{Tx}-\mathrm{Ty}) \leq \mathrm{P}_{\alpha}(\mathrm{Ix}-\mathrm{Iy}) \text {. }
$$

For each $\mathrm{P}_{\alpha} \in \mathrm{A}^{*}(\tau)$.

For simplicity, we shall call $\mathrm{A}^{*}(\tau)$-nonexpansive $\left(\mathrm{A}^{*}(\tau)-I\right.$-nonexpansive $)$ maps to non-expansive ( $I$-nonexpansive).

Definition 1.6: A self mapping $T$ of $M$ is said to be uniformly asymptotically regular on $M$ if for each $\varepsilon>$ 0 , there exists $N(\varepsilon)=N$ such that $\mathrm{P}_{\alpha}\left(\mathrm{T}^{\mathrm{n}} \mathrm{x}-\mathrm{T}^{\mathrm{n}+1} \mathrm{x}\right)<\varepsilon$, for all $n \geq N$, and $x \in M$.

Definition 1.7. A self mapping $T$ of a nonempty subset $M$ of a locally convex space $X$ is said to be;

(1) compact, if $\left\{\mathrm{x}_{\mathrm{n}}\right\}$ is a bounded sequence in $M$, then $\left\{\mathrm{T}_{\mathrm{n}}\right\}$ has a convergent subsequence $\left\{\mathrm{T} \mathrm{x}_{\mathrm{m}}\right\}$ in M.

(2) demiclosed at 0 , if for every net $\left\{\mathrm{x}_{\mathrm{n}}\right\}$ in $M$ converging weakly to $\mathrm{x}$ and $\left\{\mathrm{T} \mathrm{x}_{\mathrm{n}}\right\}$ converging strongly to $0, \mathrm{~T} \mathrm{x}=0$.

Definition 1.8: Two self mappings $T$ and $I$ defined on $M$ is said to be $R-$ commuting if

$$
P_{\alpha}(T I x-I T x) \leq R P_{\alpha}(I x-T x) .
$$


For all $x \in M$ and $P_{\alpha} \in A^{*}(\tau)$ and real number $R>0$.if $\mathrm{R}=1$ the self mappings $T$ and $I$ are said to be commuting.

Definition 1.9: Let $M$ be nonempty, $T$ and $I$-invariant and $q$-starshaped with $q \in F(I)$. Two self mappings $T$ and $I$ defined on $M$ are said to be $R$-subcommuting if for all $x \in M$ and $P_{\alpha} \in A^{*}(\tau)$ ,there exists $R>0$ such that $P_{\alpha}(T I x-I T x) \leq\left(\frac{R}{K}\right) P_{\alpha}(((1-K) q+K T x)-I x)$ for all $K \in(0,1)$. Moreover if $R=1$ The self mappings $T$ and $I$ are said to be subcommuting.

Definition 1.10: Let $\mathrm{M}$ be $\mathrm{T}$ and I-invariant and $q$-starshaped with $\mathrm{q} \in F(I)$. Two self mappings $T$ and $I$ are said to be $R$-subweakly commuting if for all $x \in M$ and $P_{\alpha} \in A^{*}(\tau)$ There exists Real number $R>0$ such that $P_{\alpha}(T I x-I T x) \leq R d_{P_{\alpha}}(I x,[q, T x])$. Such that

$$
d_{P_{\alpha}}(I x,[q, T x])=\inf \left\{P_{\alpha}(I x-y): y \in[q, T x]\right\}
$$

for all $0 \leq K \leq 1$, where, $[q, T x]=(1-K) q+K T x$.

Remark 1.11: It is clear from the definition that commuting mappings are $R$ - subcommuting and $R$ - subweakly commuting mappings are $R-$ weakly commuting mappings.

Example 1.12: Let $X=\mathbb{R}$ with norm $\|x\|=|x|$ and $=[1, \infty)$. Let two self mappings $I$ and $T$ of $M$ be defined as:

$$
\begin{gathered}
T x=x^{2} \\
I x=2 x-1
\end{gathered}
$$

Then $T$ and $I$ are $R$ - weakly commuting mappings to $\mathrm{R}=2$. But $T$ and $I$ are not $R-$ subcommuting.

Example 1.13: Let $X=[0,1]$ with Euclidean metric and define

$$
\begin{gathered}
T x=\frac{x}{x+4} \\
I x=\frac{x}{2}
\end{gathered}
$$

For $\in X$. But for any $x \neq 0$

$$
\operatorname{TI} x=\frac{x}{x+8}>\frac{x}{2 x+8}=\operatorname{ITx}
$$

Example 1.14: Let $X=\mathbb{R}$ with norm $\|x\|=|x|$ and $=[1, \infty]$. Let two self mappings $T$ and $I$ of $M$ be defined as

$$
\begin{aligned}
& T x=4 x-3 \\
& I x=2 x^{2}-1
\end{aligned}
$$

Then $M$ is $T$ and $I-$ invariant and $P-$ starshaped with $P=1 \in F(I)$ and

$$
|T I x-I T x|=24(x-1)^{2}
$$


Moreover for all $x \in M$ and $\mathrm{R}=12, P=1=F(I)$ We have

$$
|T I x-I T x| \leq\left(\frac{R}{K}\right)|K T x+(1-K) P-I x|
$$

Therefore two self mappings $T$ and $I$ are $R$ - subweakly commuting mappings, but are not commuting.

Example 1.15: Let $X=\mathbb{R}^{2}$ with norm $\|(x, y)\|=\max \{|x|,|y|\}$. And define $T$ and $I$ by

$$
\begin{gathered}
T(x, y)=\left(2 x-3, y^{3}\right) \\
I(x, y)=\left(x^{2}, y^{2}\right)
\end{gathered}
$$

Then two self mappings $T$ and $I$ are $R$ - subweakly commuting on $M=\{(x, y): x \geq 1, y \geq 1\}$

, but are not commuting.

\section{2. main result}

The following is the definition of uniformly $R$ - subweakly commuting mappings in the subset of normed space.

Definition 2.1: If $M$ is $q$ - starshaped subset of normed space with $\mathrm{q} \in \mathrm{F}(\mathrm{T})$, then $T$ and $I$ are said to be uniformly $R$ - subweakly commuting on $M \backslash\{q\}$ if there exists a real number $R>0$ such that $\left\|T^{n} I x-I T^{n} x\right\| \leq R \operatorname{dist}\left(I x,\left[T^{n} x, q\right]\right)$ for all $x \in M$ and $R>0$ where

$\operatorname{dist}\left(I x,\left[T^{n} x, q\right]\right)=\inf \left\{\left\|I x-y_{n}\right\|: y_{n} \in\left[T^{n} x, q\right]=\right.$ $\alpha_{\mathrm{n}} T^{n} x+\left(1-\alpha_{\mathrm{n}}\right) q$, where $\left\{\alpha_{\mathrm{n}}\right\}$ is a sequence of real numbers such that $0<\alpha_{\mathrm{n}}<$ 1 and $\left.\lim _{n \rightarrow \infty} \alpha_{\mathrm{n}}=1\right\}$.

Now present definition of uniformly $R$ - subweakly commuting mappings in Hausdorff locally convex space.

Definition 2.2: Let $M$ is $T$ and $I$ - invariant and $q$ - starshaped with $\mathrm{q} \in F(I)$. Two self mappings $T$ and $I$ are said to be uniformly $R$ - subweakly commuting on $M \backslash\{q\}$ if there exists a real number $R>0$ such that for all $P_{\alpha} \in A^{*}(\tau)$ and all $x \in M$ we have;

$$
P_{\alpha}\left(T^{n} I x-I T^{n} x\right) \leq R d_{P_{\alpha}}\left(I x,\left[T^{n} x\right], q\right)
$$

where,

$d_{P_{\alpha}}\left(I x,\left[T^{n} x, q\right]\right)=\inf \left\{P_{\alpha}\left(\left(I\left(x-y_{n}\right): y_{n} \in\left[T^{n} x, q\right]=\right.\right.\right.$

$\alpha_{n} T_{n} x+\left(1-\alpha_{n}\right) q$, and $\left\{\alpha_{n}\right\}$ is a sequence of real numbers such that $0<\alpha_{n}<$ 1 and $\left.\lim _{n \rightarrow \infty} \alpha_{n}=1\right\}$.

Lemma 2.3: Let $M$ be a nonempty, $\tau$-bounded and $\tau$-closed of a Hausdorff locally convex space $(\mathrm{X}, \tau)$. Let $T, I: M \rightarrow M$ be self mappings and $T(M-\{q\}) \subseteq I(M)-\{q\}$ and, suppose there exists $k \in(0,1)$ such that : 


$$
P_{\alpha}(T x-T y) \leq k m a x\left\{P_{\alpha}(I x-I y), P_{\alpha}(I x-T x), P_{\alpha}(I y-T y), \frac{1}{2}\left[P_{\alpha}(I x-T y)+P_{\alpha}(I y-T x)\right]\right\}
$$

For all $x, y \in M$ and $P_{\alpha} \in A^{*}(\tau)$. Further if $\mathrm{T}$ is continuous and $\operatorname{cl}[T(M-\{q\})]$ is $\tau-$ sequentially completely . T and I are R-weakly commuting on $M-\{q\}$. Then $\mathrm{F}(\mathrm{I}) \cap \mathrm{F}(\mathrm{T})$ is singleton.

Proof: Let $x_{0} \in M-q$. Since $(M-\{q\}) \subseteq I(M)-\{q\}$, we define a sequence $\left\{x_{\mathrm{n}}\right\}$ in $M-\{q\}$ as $I x_{n}=T x_{n-1}$ for each $n \geq 1$. Then

$$
\begin{aligned}
\mathrm{P}_{\alpha}\left(I x_{n+1}-I x_{n}\right) & =\mathrm{P}_{\alpha}\left(\mathrm{T} x_{n}-\mathrm{T} x_{n-1}\right) \\
\leq & \operatorname{kmax}\left\{\mathrm{P}_{\alpha}\left(I x_{n}-I x_{n-1}\right), \mathrm{P}_{\alpha}\left(I x_{n}-\mathrm{T} x_{n}\right), \mathrm{P}_{\alpha}\left(I x_{n-1}-\mathrm{T} x_{n-1}\right), \frac{1}{2}\left[\mathrm{P}_{\alpha}\left(I x_{n}-\mathrm{T} x_{n-1}\right)\right.\right. \\
& \left.\left.+\mathrm{P}_{\alpha}\left(\mathrm{T} x_{n}-I x_{n-1}\right)\right]\right\} \\
& =\operatorname{kmax}\left\{\mathrm{P}_{\alpha}\left(I x_{n}-I x_{n-1}\right), \mathrm{P}_{\alpha}\left(I x_{n}-I x_{n+1}\right), \mathrm{P}_{\alpha}\left(I x_{n-1}-I x_{n}\right), \frac{1}{2}\left[\mathrm{P}_{\alpha}\left(I x_{n}-I x_{n}\right)\right.\right. \\
& \left.\left.+\mathrm{P}_{\alpha}\left(I x_{n+1}-I x_{n-1}\right)\right]\right\} \\
& =\operatorname{kmax}\left\{\mathrm{P}_{\alpha}\left(I x_{n}-I x_{n-1}\right), \mathrm{P}_{\alpha}\left(I x_{n}-I x_{n+1}\right), \frac{1}{2}\left[\mathrm{P}_{\alpha}\left(I x_{n+1}-I x_{n}\right)\right.\right. \\
& =\operatorname{kmax}\left\{\mathrm{P}_{\alpha}\left(I x_{n}-I x_{n-1}\right), \mathrm{P}_{\alpha}\left(I x_{n}-I x_{n+1}\right), \frac{1}{2}\left[\mathrm{P}_{\alpha}\left(I x_{n+1}-I x_{n}\right)+\mathrm{P}_{\alpha}\left(I x_{n}-I x_{n-1}\right)\right]\right\} \\
& \leq k P_{\alpha}\left(I x_{n}-I x_{n-1}\right)
\end{aligned}
$$

For all $\mathrm{n}$. This implies that $\left\{\right.$ If $\left.x_{\mathrm{n}}\right\}$ is Cauchy sequence in $M-\{q\}$. So $\left\{\mathrm{T} x_{\mathrm{n}}\right\}$ is a Cauchy sequence in $M-\{q\}$ and since $C l[T(M)-q]$ is $\tau$-complete, $T x_{n} \rightarrow y \in M$ and consequently $x_{n} \rightarrow y$. Since T, I are $R-$ weakly commuting on $M-\{q\}, \mathrm{P}_{\alpha}\left(\mathrm{T} I x_{n}-\operatorname{IT} x_{n}\right) \leq \mathrm{RP}_{\alpha}\left(\mathrm{T} x_{n}-\mathrm{I} x_{n}\right)$

Which implies IT $x_{n} \rightarrow$ Ty as $n \rightarrow \infty$.

Since

$\mathrm{P}_{\alpha}\left(\mathrm{T} x_{n}-T \mathrm{~T} x_{n}\right) \leq \mathrm{k} \cdot \max \left\{\mathrm{P}_{\alpha}\left(\mathrm{I} x_{n}-\mathrm{ITT} x_{n}\right), \mathrm{P}_{\alpha}\left(\mathrm{I} x_{n}-\mathrm{T} x_{n}\right), \mathrm{P}_{\alpha}\left(\mathrm{IT} x_{n}-\mathrm{TT} x_{n}\right)\right.$,

$$
\left.\frac{1}{2}\left[\mathrm{P}_{\alpha}\left(\mathrm{I} x_{n}-\mathrm{TT} x_{n}\right)+\mathrm{P}_{\alpha}\left(\mathrm{IT} x_{n}-\mathrm{T} x_{n}\right)\right]\right\}
$$

Taking the limited as $n \rightarrow \infty$, We get

$$
\begin{array}{r}
\mathrm{P}_{\alpha}(\mathrm{y}-\mathrm{Ty}) \leq \mathrm{k} \cdot \max \left\{\mathrm{P}_{\alpha}(\mathrm{y}-\mathrm{Ty}), \mathrm{P}_{\alpha}(\mathrm{y}-\mathrm{y}), \mathrm{P}_{\alpha}(\mathrm{Ty}-\mathrm{Ty})\right. \\
\left.\frac{1}{2}\left[\mathrm{P}_{\alpha}(\mathrm{y}-\mathrm{Ty})+\mathrm{P}_{\alpha}(\mathrm{Ty}-\mathrm{y})\right]\right\}
\end{array}
$$

Thus $y=T y$

Suppose $y=q$. Since $T$ and $I$ are R-weakly commuting on $M-\{q\}$, it follow that $0=\mathrm{P}_{\alpha}(\mathrm{ITq}-\mathrm{TIq}) \leq \mathrm{RP}_{\alpha}(\mathrm{Tq}-\mathrm{Iq})=0$ 
A contradiction. Since $y=T y \in T(M-q)$ and $T(M-\{q\}) \subset I(M)-\{q\}$, there exists $z \in M-\{q\}$ such that $y=I f z$. Now we shall show that $I z=T z$, and

$$
\begin{aligned}
& \mathrm{P}_{\alpha}\left(\mathrm{TT} x_{n}-\mathrm{Tz}\right) \leq \mathrm{k} \cdot \max \left\{\mathrm{P}_{\alpha}\left(\mathrm{IT} x_{n}-\mathrm{Iz}\right), \mathrm{P}_{\alpha}\left(\mathrm{IT} x_{n}-\mathrm{TT} x_{n}\right), \mathrm{P}_{\alpha}(\mathrm{Iz}-\mathrm{Tz})\right. \\
& \left.\frac{1}{2}\left[\mathrm{P}_{\alpha}\left(\mathrm{IT} x_{n}-\mathrm{Tz}\right)+\mathrm{P}_{\alpha}\left(\mathrm{TT} x_{n}-\mathrm{Iz}\right)\right]\right\}
\end{aligned}
$$

Now, as $n \rightarrow \infty$ we have,

$$
\mathrm{P}_{\alpha}(\mathrm{T} y-\mathrm{Tz}) \leq \mathrm{k} \cdot \max \left\{\mathrm{P}_{\alpha}(\mathrm{Ty}-\mathrm{Iz}), \mathrm{P}_{\alpha}(\mathrm{Ty}-\mathrm{Tz}), \mathrm{P}_{\alpha}(\mathrm{Iz}-\mathrm{Tz}), \quad \frac{1}{2}\left[\mathrm{P}_{\alpha}(\mathrm{Ty}-\mathrm{Tz})+\mathrm{P}_{\alpha}(\mathrm{Iz}-\mathrm{Ty})\right]\right\} .
$$

Therefore,

$$
\begin{aligned}
& \mathrm{P}_{\alpha}(\mathrm{y}-\mathrm{Tz}) \leq \mathrm{k} \cdot \max \left\{\mathrm{P}_{\alpha}(\mathrm{y}-\mathrm{Ty}), \mathrm{P}_{\alpha}(\mathrm{y}-\mathrm{Tz}), \mathrm{P}_{\alpha}(\mathrm{y}-\mathrm{Tz}),\right. \\
& \left.\frac{1}{2}\left[\mathrm{P}_{\alpha}(\mathrm{y}-\mathrm{Tz})+\mathrm{P}_{\alpha}(\mathrm{y}-\mathrm{Tz})\right]\right\} .
\end{aligned}
$$

So,

$\mathrm{P}_{\alpha}(\mathrm{y}-\mathrm{Tz})<\mathrm{P}_{\alpha}(\mathrm{y}-\mathrm{Tz})$

Hence $y=T z=I z$.Since

$\mathrm{P}_{\alpha}(\mathrm{TIz}-\mathrm{ITz}) \leq \mathrm{RP}_{\alpha}(\mathrm{Iz}-\mathrm{Tz})$

We have,$T I z=I T z$.

Therefore, $y=T y=I y$.

Theorem 2.4: Let $T$ and $I$ be continuous self mappings of a nonempty, $\tau$-bounded, $\tau$-closed, $\tau$-sequentialluy complete and $q$-starshaped subset $M$ of a Hausdorff locally convex space (X, $\tau)$. Suppose $I$ is $A^{*}(\tau)$-nonexpansive and affine with respect to $q \in F(I)$ and $I(M)=M$ and $T(M \backslash\{q\}) \subseteq$ $I(M)-\{q\}$ if $T, I$ are uniformly $R$ - subweakly commuting and $T$ is $I-$ nonexpansive and there exists a sequence $\left\{K_{n}\right\}$ of real numbers with $K_{n} \geq 0$ and $\lim _{n \rightarrow \infty} K_{n}=1$ such that $T$ is uniformly asymptotically regular satisfying

$$
\begin{aligned}
& P_{\alpha}\left(T^{n} x-T^{n} y\right) \\
& \quad \leq K_{n} \max \left\{P_{\alpha}(I x-I y), \operatorname{dist}\left(I x,\left[T^{n} x, q\right]\right), \operatorname{dist}\left(I y,\left[T^{n} y, q\right]\right), \frac{1}{2}\left[\operatorname{dist}\left(I x,\left[T^{n} y, q\right]\right)\right.\right. \\
& \left.\left.+\operatorname{dist}\left(I y,\left[T^{n} x, q\right]\right)\right]\right\}
\end{aligned}
$$

For all $x, y \in M$ and $P_{\alpha} \in A^{*}(\tau)$ and $n \in \mathbb{N}$.

Then $T$ and $I$ have a common fixed point provided any one of the following condition hold:

1) $\operatorname{cl}[T(M \backslash\{q\})]$ is $\tau$-sequentially compact ; 
2) $M$ is weakly compact and $\left(I-T^{m}\right)$ is demiclosed in 0 .

Proof: For each $n \geq 1$, define $T_{n}$ on $M$ by $T_{n}=\mu_{n} T^{n} x+\left(1-\mu_{n}\right) q$, for all $x \in M$. Where $\mu_{n}=\frac{\lambda_{n}}{K_{n}}$ and $\left\{K_{n}\right\}$ is a sequence of real numbers with $0<\lambda_{n}<1$ such that $\lim _{n \rightarrow \infty} \lambda_{n}=1$ and $\left\{K_{n}\right\}$ is defined as above. Let $T_{n}$ is a self mappings on $M$ such that $T(M \backslash\{q\}) \subseteq I(M)-\{q\}$, from uniformly $R-$ sub weakly commuting of $T$ and $I$ on $M \backslash\{q\}$, since $I$ is affine with respect to $q$, it follow that;

$$
P_{\alpha}\left(T_{n} I x-I T_{n} x\right)=\mu_{n} P_{\alpha}\left(T^{n} I x-I T^{n} x\right) \leq R \mu_{n} d_{P_{\alpha}}\left(I x,\left[T^{n} x, q\right] \leq R \mu_{n} d_{P_{\alpha}}\left(I x-T_{n} x\right) .\right.
$$

For all $x \in M \backslash\{q\}$, which it implies $T_{n}$ and $f$ are $\mu_{n} R-$ subweakly commuting .Hence by lemma 2.3 ,there exists $\left\{x_{n}\right\}$ such that $T_{n} x_{n}=I x_{n}=x_{n}$. Hence $\mu_{n} T^{n} x+\left(1-\mu_{n}\right) q=I x_{n}=x_{n}$. Also,

$$
\begin{aligned}
P_{\alpha}\left(x_{n}-T^{n} x_{n}\right) & =P_{\alpha}\left(T_{n} x_{n}-T^{n} x_{n}\right) \\
& =P_{\alpha}\left(\mu_{n} T^{n} x_{n}+\left(1-\mu_{n}\right) q-T^{n} x_{n}\right) \\
& =\left(1-\mu_{n}\right) P_{\alpha}\left(q-T^{n} x_{n}\right)
\end{aligned}
$$

Since $T(M \backslash\{q\})$ is $\tau$-bounded as $\mu_{n} \rightarrow \infty$ and $P_{\alpha}\left(x_{n}-T^{n} x_{n}\right) \rightarrow 0$ as $n \rightarrow \infty$. Therefore

$$
\begin{aligned}
\mathrm{P}_{\alpha}\left(x_{n}-\mathrm{T} x_{n}\right) \leq & \mathrm{P}_{\alpha}\left(x_{n}-T^{\mathrm{n}} x_{n}\right)+\mathrm{P}_{\alpha}\left(T^{\mathrm{n}} x_{n}-T^{\mathrm{n}+1} x_{n}\right)+\mathrm{P}_{\alpha}\left(T^{\mathrm{n}+1} x_{n}-\mathrm{T} x_{n}\right) \\
\leq & \mathrm{P}_{\alpha}\left(x_{n}-T^{\mathrm{n}} x_{n}\right)+\mathrm{P}_{\alpha}\left(T^{\mathrm{n}} x_{n}-T^{\mathrm{n}+1} x_{n}\right)+\mathrm{P}_{\alpha}\left(T\left(T^{\mathrm{n}} x_{n}\right)-\mathrm{T} x_{n}\right) \\
= & \mathrm{P}_{\alpha}\left(x_{n}-T^{\mathrm{n}} x_{n}\right)+\mathrm{P}_{\alpha}\left(T^{\mathrm{n}} x_{n}-T^{\mathrm{n}+1} x_{n}\right) \\
+ & k_{1} \cdot \max \left\{\mathrm{P}_{\alpha}\left(I T^{\mathrm{n}} x_{n}-\mathrm{I} x_{n}\right), \mathrm{P}_{\alpha}\left(I x_{n}-\mathrm{T} x_{n}\right), \mathrm{P}_{\alpha}\left(I T^{\mathrm{n}} x_{n}-T T^{\mathrm{n}} x_{n}\right),\right. \\
& \left.\frac{1}{2}\left[\mathrm{P}_{\alpha}\left(I x_{n}-T^{\mathrm{n}+1} x_{n}\right)+\mathrm{P}_{\alpha}\left(I T^{\mathrm{n}} x_{n}-\mathrm{T} x_{n}\right)\right]\right\} \\
\leq & \mathrm{P}_{\alpha}\left(x_{n}-T^{\mathrm{n}} x_{n}\right)+\mathrm{P}_{\alpha}\left(T^{\mathrm{n}} x_{n}-T^{\mathrm{n}+1} x_{n}\right)+k_{1} \mathrm{P}_{\alpha}\left(I T^{\mathrm{n}} x_{n}-I x_{n}\right) \\
= & \mathrm{P}_{\alpha}\left(x_{n}-T^{\mathrm{n}} x_{n}\right)+\mathrm{P}_{\alpha}\left(T^{\mathrm{n}} x_{n}-T^{\mathrm{n}+1} x_{n}\right)+K_{1} \mathrm{P}_{\alpha}\left(\mathrm{I}\left(\mathrm{T}^{\mathrm{n}} \mathrm{x}_{\mathrm{n}}-\mathrm{x}_{\mathrm{n}}\right) .\right.
\end{aligned}
$$

Since $I$ is continuous and affine with respect to , and $T$ is uniformly asymptotic regular, it follow that $\mathrm{P}_{\alpha}\left(x_{n}-T^{\mathrm{n}} x_{n}\right) \rightarrow 0$ as $n \rightarrow \infty$.

Since $\operatorname{ClT}(M-\{q\})$ is $\tau$ - compact, there exist a subsequence $\left\{x_{\mathrm{m}}\right\}$ of $\left\{x_{\mathrm{n}}\right\}$ such that $x_{\mathrm{m}} \rightarrow \mathrm{y} \in \mathrm{M}$ (1) as $\rightarrow \infty$. $T$ is continuous, it follow that

$$
T x_{m} \rightarrow T y=y
$$

Moreover, $T(M-\{q\}) \subseteq I(M)-\{q\}$ implies $y=T y=I z$ for some $\mathrm{z} \in M$.

$$
\begin{aligned}
& \mathrm{P}_{\alpha}\left(T x_{m}-\mathrm{Tz}\right) \leq k_{1} \cdot \max \left\{\mathrm{P}_{\alpha}\left(I x_{m}-\mathrm{Iz}\right), \mathrm{P}_{\alpha}\left(I x_{m}-\mathrm{T} x_{\mathrm{m}}\right), \mathrm{P}_{\alpha}(I z-\mathrm{Tz}), \frac{1}{2}\left[\mathrm{P}_{\alpha}\left(I x_{m}-\mathrm{Tz}\right)+\mathrm{P}_{\alpha}\left(\mathrm{T} x_{m}-\mathrm{Iz}\right)\right\}\right. \\
& \leq k_{1} \mathrm{P}_{\alpha}\left(I x_{m}-\mathrm{Iz}\right)=k_{1} \mathrm{P}_{\alpha}\left(x_{m}-\mathrm{y}\right), \text { therefore }
\end{aligned}
$$


$T x_{\mathrm{m}} \rightarrow T z$, As $\mathrm{m} \rightarrow \infty$. Hence, $y=T z=T y=I z$.Now

$$
\mathrm{P}_{\alpha}(I y-\mathrm{Ty})=\mathrm{P}_{\alpha}(I T z-\mathrm{TIz}) \leq R \mathrm{P}_{\alpha}(T z-\mathrm{Iz})=0
$$

Which implies $\mathrm{Ty}=I y=y$.

(2) Since $M$ is weakly compact, there exist a subsequence $\left\{x_{m}\right\}$ of $\left\{x_{n}\right\}$ converging weakly to some $\mathrm{y} \in M$.But $\mathrm{I}$ is affine and continuous in weakly topology in Hausdorff Spaces, it follow that $I y=y$.

Now the demiclosed of $\left(I-T^{m}\right)$ at 0 guarantees that $\left(I-T^{m}\right) \mathrm{y}=0$. Hence $T^{m} y=y$. Now we shall show that $\mathrm{Ty}=\mathrm{y}$. Since

$$
\begin{aligned}
\mathrm{P}_{\alpha}\left(T y-T^{m} \mathrm{y}\right) & =\mathrm{P}_{\alpha}\left(T y-\mathrm{T}\left(T^{m-1}\right) \mathrm{y}\right) \\
& \leq k_{1} \cdot \max \left\{\mathrm{P}_{\alpha}\left(I \mathrm{y}-\mathrm{I} T^{m-1} \mathrm{y}\right), \mathrm{d}_{\mathrm{P}_{\alpha}}(\mathrm{Iy},[\mathrm{Ty}, \mathrm{q}]), \mathrm{d}_{\mathrm{P}_{\alpha}}\left(\mathrm{I} T^{m-1} \mathrm{y},\left[\mathrm{TT} T^{m-1} \mathrm{y}, \mathrm{q}\right]\right),\right. \\
& \left.\frac{1}{2}\left[\mathrm{~d}_{\mathrm{P}_{\alpha}}\left(\mathrm{Iy},\left[\mathrm{TT} T^{m-1} \mathrm{y}, \mathrm{q}\right]\right)+\mathrm{d}_{\mathrm{P}_{\alpha}}\left(\mathrm{I} T^{m-1} \mathrm{y},[\mathrm{Ty}, \mathrm{q}]\right)\right]\right\}
\end{aligned}
$$

Let $m \rightarrow \infty$ we have,

$$
\mathrm{P}_{\alpha}(T y-\mathrm{y}) \leq k_{1} \max \left\{\mathrm{P}_{\alpha}(\mathrm{y}-\mathrm{y}), \mathrm{d}_{\mathrm{P}_{\alpha}}\left(\mathrm{Iy}-\mathrm{T}_{1} \mathrm{y}\right), \mathrm{P}_{\alpha}\left(\mathrm{Iy}-\mathrm{T}_{\mathrm{m}} \mathrm{y}\right), \frac{1}{2}\left[\mathrm{P}_{\alpha}\left(\mathrm{y}-\mathrm{T}_{\mathrm{m}} \mathrm{y}\right)+\mathrm{P}_{\alpha}(\mathrm{y}-\mathrm{Ty})\right]\right\} \quad .
$$

A contradiction, hence $\mathrm{Ty}=\mathrm{y}$ which implies $I y=T y=y$.

\section{REFERENCES}

[1] F. Akbar and A. R. Khan, Common fixed point and approximation results for noncommuting maps on locally convex spaces, Fixed point theory and applications, 2009article ID 207503, pp.14 pages(2009). [2] I. Beg, D.R. Sahu and S.D. Diwan, Approximation of fixed points of uniformly R_subweakly commuting mappings, J.Math,Anal.appl,

[3] Y.J. Cho, D.R. Sahu, J.S. Jung, Approximation of fixed points of asymptotically pseudocontractiv mappings in Banach Spaces, Southwest.J.Pure.Appl.Math,2, 49-59(2003).

[4] K. Goebel ,W.A. Kirk, A fixed point theorem for asymptotically nonexpansive mappings, Proc.Amer.Math.Soc.35, 171-174(1972).

[5] N. Hussain, G. Jungck, Common fixed points and invariant approximation results for noncommuting generalized $(f, g)$ nonxpansive maps, J.Math,Anal.appl,in press.

[6] N. Hussain, V. Berinde, Common fixed point theorem for $C_{q}$-commuting mappings in certain metrizable topological vector spaces, Fixed point Theorey and applications, 2006 article ID 23582,1-13. 552. (2006),

[7] G. Kothe, Topological Vector Spaces, Springer verlag, New York, (1969).

[8]H. Shojaei, R. Mortezaei common fixed point for affine self-maps invariant approximation in pnormed space, J. Math. Computer Sci., 6, pp- 201(2013).

[9] H. Shojaei, K. Banaei, N. Shojaei, , J. Math. Computer Sci., 6, pp- 118-128(2013).

[10] H. Shojaei, R. Mortezaei, j. Math. . Computer Sci., 6, pp201-209 (2013). 
[11] J. Schu, Iterative approximation of fixed points of nonexpansive mappings with starshaped domain, Comment.Math Univ.Carolin. 31(2) 277-282(1990).

[12] J. Schu, Approximation of fixed points of asymptotically nonexpanisve mappings , Proc. Amer. Math. Soc. 112(1) 143-151(1991).

[12] N. Shahzad, Invariant approximations, generalized $I$-contractions, and $R$-subweakly commuting maps, Fixed Point Theory and Applications.179-86(2005). 